\title{
Optimality Theoretic Representation of Stress in Cairene Arabic
}

\author{
Rajaa Aquil \\ School of Modern Languages, Georgia Institute of Technology, Atlanta, USA \\ Email: rajaa.aquil@modlangs.gatech.edu \\ Received July 13 $3^{\text {th }}, 2012$; revised August $13^{\text {th }}, 2012$; accepted August $20^{\text {th }}, 2012$
}

\begin{abstract}
Stress pattern of Cairene Arabic (CA) has played a major role in the development of stress placement theory. Syllable weight plays a role, however, the weight to stress principle does not always apply. Bimoracity of a foot is very important and is largely addressed in the literature. Stress in CA is described in the literature as Moraic Trochee, but primary stress is on one of the three leftmost syllables. Many studies investigated primary stress in CA. These studies employed different theoretic formulations based on the segmental rules, the metrical phonological tree, and the metrical phonological grid. Notwithstanding, no recent study has translated the findings of the aforementioned literature into an Optimality Theoretic Constraints framework. The present paper attempts to accomplish this feat. The paper also presents a new set of data based on CA spoken language.
\end{abstract}

Keywords: Cairene Arabic Primary Stress; Optimality Theoretic Framework; Constraints Hierarchy; Cairene Arabic Spoken Data

\section{Introduction}

The stress pattern of Cairene Arabic (CA) has played a major role in the development of metrical and stress placement theory (Halle \& Vergnaud, 1987; Hayes, 1995; Prince, 1983; Selkirk, 1984). There is no dispute over the place of primary stress in $\mathrm{CA}$, namely, it is on one of the rightmost three syllables (Gairdner, 1926; Halle \& Vergnaud, 1987; Harms, 1981; Harrell, 1957; Hayes, 1995; McCarthy, 1979; Mitchell, 1956, 1960a; Welden, 1980).

1) a) Stress the penult, whether light or heavy.

$\begin{array}{lll}\text { i) } & \text { bána } & \text { he built } \\ \text { ii) } & \text { fíhim } & \text { he understood(3rd sg, m) } \\ \text { iii) } & \text { mibáћbah } & \text { easygoing }\end{array}$

b) Stress the final if superheavy.

\begin{tabular}{|c|c|c|}
\hline i) & barabánd & one who talks very \\
\hline i) & mutaSallaqáat & belongings \\
\hline iii) & baraníit $^{\mathrm{S}}$ & hats \\
\hline
\end{tabular}

c) Stress the antepenult or the penult, whichever is separated by an even number of syllables from the immediately preceding heavy syllable or the beginning of the word (where zero separation is counted as even).
i) šágara
a tree
ii) Pibtádaৎ
invented
iii) sabahlála
haphazard

Formulations of primary stress have had different representations, e.g., rule-based stress assignment (Chomsky \& Halle, 1986, 1991), metrical phonological tree (Liberman \& Prince, 1977) and metrical phonological grid (Halle \& Vergnaud, 1987).

2) Segmental Rule-Based (Welden, 1980).

$\mathrm{S}$ is either a heavy syllable $(\mathrm{H})$ or a light syllable $(\mathrm{L})$

$\mathrm{S} \rightarrow[+$ stress $] /\langle \#(\mathrm{X} \mathrm{H})\rangle$ $(\langle\mathrm{L}\rangle \mathrm{L}) \# \#\langle\mathrm{~L}\rangle$

The rules abbreviate the following environments.

i) Stress the antepenult if it is a light syllable, right after a heavy syllable or starting the word, as in a) and b).

ii) Or stress the penult, as in c) or the final elsewhere, as in d).

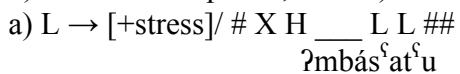

b) $\mathrm{L} \rightarrow[+$ stress $] / \# \quad$ L L \#\# kátabu

c) $\mathrm{S} \rightarrow[+$ stress $] /$ L \# \# ráma

d) $\mathrm{S} \rightarrow[0+$ stress $] /$ _ \#\# šáaf ' 'a library' 'he saw' katabuiu $<\mathrm{h}>\quad$ 'they wrote it' kitáab 'book'

It is well known that segmental rule-based theory was not adequate to represent all stress-related phenomena, especially the internal structure of a syllable and its role in determining where stress is placed. For example, rules could not capture the hierarchical structure of a syllable structure, as the syllable cannot be explained in a single line or linear approach. This led researchers to adopt nonlinear phonological theories, e.g., metrical tree phonology and metrical grid phonology, to capture prosodic phenomena that were not straightforwardly represented in the segmental rule-based theory. The following metrical phonological tree and metrical phonological grid structures 3) demonstrate the representation of the primary stress in the word [Sasaliyyáaya] 'kind of candy'.

3) a) Metrical Phonology Tree

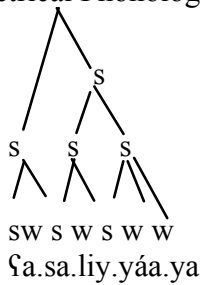

b) Metrical Phonology Grid

$2(\quad *)$ Prosodic word level
$1(*)(*)(*) \quad$ Foot level
$0 * * * * * * \quad$
$\mu \quad \mu \mu \mu \mu \mu \mu$ Mora level
Ya.sa.liy.yáa.ya


However, to my knowledge, no study has ever translated the findings of the literature in relation to primary stress in CA into an Optimality Theoretic Framework ${ }^{1}$. In this paper I attempt to accomplish this feat.

The data set analyzed in this paper is drawn from Cairene spoken $\mathrm{Arabic}^{2}$. Studies conducted on Arabic so far have either focused on Classical or Modern Standard Arabic, and on Classical Arabic as pronounced by Egyptian or Cairene ${ }^{3}$ Arabic speakers, what has come to be known as Egyptian Radio Arabic (Halle \& Vergnaud, 1987; Hayes, 1995; Kenstowicz, 1980; McCarthy, 1979; Mitchell, 1960b). As a result, the findings and motivating models available in the literature are, for the most part, based on the Cairene pronunciation of Classical Arabic, a variety that may exhibit two different stress systems: Cairene Arabic and Classical Arabic pronounced in a Cairene way. The literature motivates the inclusion of Classical Arabic since it supplies the data with a wider array of possible syllabic shapes, and thus provides a stiffer test for any proposed model (Hayes, 1995: p. 67).

Because studies investigating the stress pattern of CA have generally looked at the CA pronunciation of Classical or Modern Standard Arabic norms, I set on analyzing a CA data set independent of Classical, in order to present a stress account that is based solely on uniquely CA phonetic outputs.

The CA data in (1) show that stress in CA words is placed on the penult, whether it is heavy or light, but may also be placed on the ultimate final syllable if it is super-heavy or on the antepenult whether it is light or heavy. Therefore, neither position nor weight is the sole decisive factor in determining where stress should fall.

From the data-set in 1) we can reach the following generalizations:

4) Generalizations on stress

a) Monosyllabic words must be bimoraic

b) Main stress in bisyllabic (LL) words is on the left syllable.

c) In a polysyllabic word, the main stress must fall on the rightmost light or heavy syllable.

d) Stress does not fall on a final CVC syllable.

e) Stress falls on a final syllable only when it is CVV or super-heavy, i.e., CVCC or CVVC.

Well-established phonological analyses of minimal word requirements in the literature demonstrate that some languages require content words to be of some minimal size, often two syllables or two moras (Kenstowicz, 1994). In CA, a monosyllabic content word must be superheavy, CVVC or CVCC. A final consonant does not add to the weight of a syllable, so only

\footnotetext{
${ }^{1}$ Optimality Theory (McCarthy \& Prince, 1993a; Prince \& Smolensky, 1993, 2004) is a constraint-based approach to phonological well-formedness. It posits that Universal Grammar has a set of violable universal constraints (CON). These constraints encompass universal properties of languages. All universal constraints are available in every language in the world. However, each language has its particular ranking of these constraints, i.e., a certain hierarchy. Some languages may rank a certain constraint high in its hierarchy while others may rank the same constraint very low. This difference in constraint ranking explains the variation that arises between languages. In addition Optimality Theory (OT) adopts a representational framework in which the candidate that optimally satisfies a given constraint ranking wins over all other candidates produced by GEN (the generator that creates linguistic candidates). The grammar decides on the winner through EVAL, which selects the best candidate that satisfies the high-ranked constraints. ${ }^{2} \mathrm{CA}$ data was extracted from (Badawi \& Hinds, 1986), A dictionary of Egyptian Arabic.

${ }^{3}$ Egyptian and Cairene Arabic refer to the same main dialect spoken particularly in the Egyptian capital of Cairo, and the delta.
}

superheavy syllables reach the minimum size of two moras. As a result, a degenerate foot must be forbidden - a conclusion also reached by Watson (2002) within autosegmental phonological theory.

Since super heavy syllables attract stress, we can infer that a constraint, which prefers weight to be stressed, must be at play. Likewise, since stress falls on one of the last three right-most syllables, an alignment constraint favoring the right edge of the word must also be at play in stress assignment. Directionality of how feet are constructed also plays a role in where stress falls, as exemplified in [šágara] in (c)1 where stress is on a leftmost, rather than the rightmost syllable. Finally, we realize from the data that final CVC and CVV act differently. The former does not attract stress, but the latter does.

I propose an Optimality Theoretic (OT) analysis in tableau (Tableaux 1-11) using violable as well as un-dominated constraints. This analysis demonstrates and represents straight forwardly and economically the optimal place where primary stress docks in a word. The following constraints are at play.

\section{Optimality Constraints Ranking Approach}

OT adopts a representational framework in which the optimal candidate that satisfies the high-ranked constraint wins over all other candidates produced by GEN (the generator that creates linguistic candidates). The grammar decides on the winner through EVAL, which selects the best candidate that satisfies the high-ranked constraints. In addition, the grammar decides on surface forms; therefore, there is no resort to ordering rules. In OT, forms are marked with respect to some constraint if they violate it. These forms are literally marked in that they incur violation marks for the constraint as part of their grammatical derivation. In this way, these forms or candidates are considered losers and an $[\mathrm{L}]^{4}$ is marked in the column of the given constraint. The constraints in 5) are considered to have a role in stress placement in CA.

5) Prosodic and stress constraints in $\mathrm{CA}$

FOOT BINARITY (FTBIN)

Feet must be binary under syllabic or moriac analysis

(McCarthy \& Prince, 1986, 1990, 1993b; Prince, 1980).

Weight-to Stress Principle (WSP)

Heavy syllables must be stressed (Prince \& Smolensky, 1993, 2004).

PARSE-Syllable (PARSE- $\sigma$ )

A syllable must be footed (Prince \& Smolensky, 1993, 2004).

Foot-form (trochaic) (TR)

Leftmost position of the foot is the head of the foot

This constraint requires feet to be left headed and accounts for the trochaic form of the disyllabic feet (Prince \& Smolensky, 1993, 2004).

PARSE Segment (PARSE SG)

All segments of a syllable must be linked to the level immediately above (McCarthy, 2008).

${ }^{4}$ I adopt Prince (2002) and McCarthy (2008) comparative or combination tableau, because combination tableau illustrates the ranking between constraints as well as violation marks. In the tableau, each losing candidate is compared to the winning candidate in regards to each and every constraint. (W) denotes that the constraint in question prefers the winner rather than the given candidate. Whereas the $(\mathrm{L})$ denotes that the given constraint prefers the losing candidate rather than the winner. Blank cells in a combination tableau denote that the constraint that has the blank cells in its column does not have a preference. 
ALIGN (Foot, L, PrWd, L) (AFL)

All feet aligned left

ALIGN the left edge of each foot with the left edge of some prosodic word (McCarthy \& Prince, 1993).

ALIGN (Foot, R, PrWd, R) (AFR)

All feet aligned right

ALIGN the right edge of each foot with the right edge of some prosodic word (McCarthy \& Prince, 1993).

ALIGN HEAD (Prwd), R Prwd, R (ALIGN HEAD/R)

Main stress of the word is rightmost

ALIGN the head foot of a prosodic word with the right edge of a prosodic word (McCarthy \& Prince, 1993).

\section{FootBinarity $>>$ Trochaic, PARSE- $\sigma$, PARSE-SEG, ALIGN-FOOT-L}

Because minimal word requirement is adhered to in CA, as noted above, FtBin must have a very important role in the prosody of CA and should accordingly be high ranked. Tableau 1 illustrates the interaction between FTBIN, which stipulates that a foot consist of two moras, and PARSE SG, which specifies that all the segments of a syllable should be parsed.

Tableau 1 shows that there is a direct ranking between FTBIN and PARSE- $\sigma$. No ranking is evident between PARSE- $\sigma$ and PARSE SG, as the two are in a stringency relationship ${ }^{5}$, i.e., every violation of PARSE- $\sigma$ is also a violation of PARSE SG, but the reverse is not the case. In Tableau 1 candidate (a) is the optimal candidate because it does not violate FTBIN. Candidates (b) and (c) lose because they violate FTBIN. Candidate (b) satisfies PARSE- $\sigma$ by parsing all the syllables, and it also satisfies PARSE SG by parsing the last consonant in the word. However, by satisfying these two constraints, candidate (b) violates FTBIN when it parses a degenerate foot that is not of two moras (i.e., [li]) and when it parses the last consonant. By parsing the last consonant, the final syllable becomes trimoraic.

Tableau 2 illustrates the ranking between FOOTBINARITY and TROCHAIC.

Tableau 2 demonstrates that FTBIN dominates both PARSE$\sigma$ and TROCHAIC. The most optimal candidate is (a) since it obeys FTBIN constraint at the expense of TROCHAIC and PARSE- $\sigma$. Candidate (b) loses because it parses a degenerate foot (i.e., [mi]), whereas candidates (c) and (d) lose because a foot exceeds two moras. Candidate (d) loses in spite of the fact that it follows the default stress pattern of disyllabic words, namely trochaic. Note the high ranking of FTBIN so far. TROCHAIC also is one of the high-ranked constraints in CA. The Tableau below demonstrates TROCHAIC dominating PARSE- $\sigma$.

In Tableau 3 candidate (a) bears stress on the left syllable in the final $(\mathrm{L}, \mathrm{L})$ foot, following the trochaic rhythmic pattern. Although candidate (b) satisfies PARSE- $\sigma$, it loses because it violates a higher ranked constraint, Trochaic.

\section{ALIGN-FOOT-L >> ALIGN-FOOT-R}

Foot construction proceeds from left to right, as mentioned above. Tableau 4 demonstrates the constraints responsible for the directionality of foot construction in CA.

The Tableau provides evidence that foot construction in CA is aligned at the left edge of the word. Candidate (a) wins, as it obeys high-ranked constraints namely, FTBIN, Troachiac, and

${ }^{5}$ The interested reader may refer to McCarthy (2008: p. 65). it does not violate AFL. Other candidates (b), (c), and (e) violate AFL and the highly ranked FTBIN and Troachiac constraints. Candidate (d) does not obey AFL. It constructs the foot on the right and has the stress on the left syllable of the final disyllabic syllable.

\section{PARSE- $\sigma>>$ ALIGN-FOOT-L (AFL)}

The interaction between PARSE- $\sigma$ and ALIGN-FOOT-L is illustrated in Tableau 5.

Tableau 5 demonstrates PARSE- $\sigma$ dominating AFL. Candidate (a) is the optimal one because it minimally violates PARSE- $\sigma$. Candidate (b) loses to candidate (a) because, by satisfying AFL and aligning all feet to the left edge of the word, three violations of PARSE- $\sigma$ occur.

Tableau 1.

FTBIN $>>$ PARSE- $\sigma$, PARSE-SG.

\begin{tabular}{lccc}
\hline /mutaSalliqaat/ ‘belongings' & FTBIN & PARSE- $\sigma$ & PARSE-SG \\
\hline$\sigma$ a. (muta)(Yal)li(qáa) $<\mathrm{t}>$ & & ${ }^{*}$ & ${ }^{*}$ \\
b. (muta)(Gal)(li)(qáat) & ${ }^{*} \mathrm{~W}$ & $\mathrm{~L}$ & $\mathrm{~L}$ \\
c. (múta)(Gal)li(qaat) & ${ }^{* *} \mathrm{~W}$ & ${ }^{*}$ & \\
\hline
\end{tabular}

Tableau 2.

FTBIN $>>$ Trochaic (TR), PARSE- $\sigma$.

\begin{tabular}{lccc}
\hline /banaa/ 'he built it' & FTBIN & TR & PARSE- $\sigma$ \\
\hline o. ba (náa) & & & $*$ \\
b. (ba) (náa) & ${ }^{*} \mathrm{~W}$ & ${ }^{*} \mathrm{~W}$ & $\mathrm{~L}$ \\
c. (banáa) & ${ }^{*} \mathrm{~W}$ & ${ }^{*} \mathrm{~W}$ & $\mathrm{~L}$ \\
d. (bánaa) & ${ }^{*} \mathrm{~W}$ & $\mathrm{~L}$ & $\mathrm{~L}$ \\
\hline
\end{tabular}

Tableau 3.

Trochaic (TR), >> PARSE- $\sigma$.

\begin{tabular}{lcc}
\hline /sabahlala/ 'haphazardly' & TR & PARSE- $\sigma$ \\
\hline o. sa(bah)(lála) & & ${ }^{*}$ \\
b. (sa)(bah)(lalá) & ${ }^{*} \mathrm{~W}$ & $\mathrm{~L}$ \\
\hline
\end{tabular}

Tableau 4

ALIGN-FOOT-L (AFL) >>ALIGN-FOOT-R (AFR).

\begin{tabular}{lccccc}
\hline /šagara/ 'tree' & FTBIN & TR & AFL & AFR & PARSE- $\sigma$ \\
\hline o a. (šága)ra & & & & ${ }^{*}$ & ${ }^{*}$ \\
b. (śága)(ra) & ${ }^{*} \mathrm{~W}$ & & ${ }^{*} \mathrm{~W}$ & $\mathrm{~L}$ & $\mathrm{~L}$ \\
c. (ša)(gára) & ${ }^{*} \mathrm{~W}$ & & ${ }^{*} \mathrm{~W}$ & $\mathrm{~L}$ & $\mathrm{~L}$ \\
d. ša(gára) & & & ${ }^{*} \mathrm{~W}$ & $\mathrm{~L}$ & ${ }^{*}$ \\
e. ša(gará) & & ${ }^{*} \mathrm{~W}$ & ${ }^{*} \mathrm{~W}$ & $\mathrm{~L}$ & ${ }^{*}$ \\
\hline
\end{tabular}

Tableau 5.

PARSE- $\sigma>>$ ALIGN-FOOT-L.

\begin{tabular}{lcc}
\hline Yàsaliyyáaya ‘kind of candy' & PARSE- $\sigma$ & AFL \\
\hline a. (Gàsa)(liy)(yáa)ya & ${ }^{*}$ & ${ }^{* *}$ \\
b. (Gàsa) liyyaaya & ${ }^{* * *} \mathrm{~W}$ & $\mathrm{~L}$ \\
\hline
\end{tabular}




\section{WSP $>$ PARSE- $\sigma$}

Returning to the role weight plays in stress assignment in CA, we note from Tableau 6 that weight dominates PARSE- $\sigma$.

The optimal candidate in Tableau 6 is (a) because it does not violate WSP, whereas candidate (b) does. Candidate (a) obeys WSP while minimally violating PARSE- $\sigma$, a low-ranked constraint. Although candidate (b) fulfills PARSE- $\sigma$ by parsing all syllables of the word, it loses because it does not obey WSP; stress is assigned to a light syllable (i.e., [títa]).

The interaction between FtBin and Wspis illustrated in Tableau 7, which demonstrates that FtBin dominates WSP.

FTBIN favors candidate (a) over candidate (b). In candidate (b) the stress moves to a heavy syllable, thus satisfying WSP, but by parsing a degenerate foot [mu] FTBIN is violated. In fact FTBIN is shown to dominate both WSP and PARSE- $\sigma$, a finding in line with rankings already established in Tableau 1 above (FTBIN $>>$ PARSE- $\sigma$ ).

\section{ALIGN-HEAD/R $>$ WSP}

Heavy syllables, as mentioned earlier, play a role in attracting stress. However, a heavy syllable does not always attract stress in CA words such as (cf. 1 a ii [(fi)(him)]). This suggests that there is a more important constraint at play, which pressures stress to fall on a light syllable rather than a heavy one as long as the light syllable is among the last three rightmost syllables of the word (see 000 [sa(bah)(lála)]). Tableau 8 demonstrates the interaction between WSP and that of ALIGN-HEAD/ $\mathrm{R}$, which is responsible for the main stress of a prosodic word.

Candidate (a) wins, although it does not fulfill WSP, since stress falls on a light syllable (i.e., [Cádi] instead of the preceding antepenultimate heavy syllable [dal]. Candidate (b) obeys WSP, but violates a higher-ranked constraint, ALIGN-HEAD/R, and hence loses to the winner (a). The Tableau illustrates the domination of ALIGN-HEAD/R over WSP.

Tableau 6.

WSP $>>$ PARSE- $\sigma$.

\begin{tabular}{|c|c|c|}
\hline $\begin{array}{l}\text { /Piftitahiyya/ } \\
\text { 'inauguration' }\end{array}$ & WSP & PARSE- $\sigma$ \\
\hline a. (2if)(tita)(híy)ya & & * \\
\hline b. (Pif)(títa)(hiy)(ya) & ${ }^{*} \mathrm{~W}$ & $\mathrm{~L}$ \\
\hline
\end{tabular}

Tableau 7.

FTBIN $>>$ WSP $>>$ PARSE- $\sigma$.

\begin{tabular}{lccc}
\hline $\begin{array}{l}\text { /musalsala/ } \\
\text { 'TV series' }\end{array}$ & FTBIN & WSP & PARSE- $\sigma$ \\
\hline$\sigma$ a. mu(sal)(sála) & & $*$ & $*$ \\
b. (mu)(sál)(sala) & ${ }^{*} \mathrm{~W}$ & $\mathrm{~L}$ & $\mathrm{~L}$ \\
\hline
\end{tabular}

Tableau 8.

ALIGN-HEAD/R >> WSP.

\begin{tabular}{lcc}
\hline $\begin{array}{l}\text { /PiddalGadi/ } \\
\text { 'term used by women' }\end{array}$ & ALIGN-HEAD/R & WSP \\
\hline a. (Pid)(dal)( Cádi) & & $*$ \\
b. (Pid)(dál)( ( Gadi) & W & L \\
\hline
\end{tabular}

While ALIGN-HEAD/R dominates WSP in the previous tableau, ALIGN-HEAD/R also dominates PARSE- $\sigma$ in Tableau 9. The tableau demonstrates the direct ranking between ALIGN-HEAD/R and PARSE- $\sigma$. Candidate (b) loses to candidate (a) because stress is not rightmost. Although candidate (b) satisfies PARSE- $\sigma$ by parsing every syllable of the word, it loses because ALIGN-HEAD/R dominates PARSE- $\sigma$.

Thus, based on the analysis so far, we can rank the relevant constraints as follows:

6) FTBIN $>>$ Trochaic

FTBIN $\gg$ PARSE- $\sigma$

FTBIN $>$ WSP

ALIGN-HEAD/R $>>$ WSP $>>$ PARSE- $\sigma$, PARSE SG $>>$ AFL

So far FTBIN is undominated. ALIGN-HEAD/R is high ranked and dominates lower-ranked constraints WSP, PARSE- $\sigma$, and PARSE SG and AFL. Additionally, WSP dominates PARSE- $\sigma$, and PARSE SG. A direct ranking between PARSE- $\sigma$ and PARSE SG cannot be established, since they are in a stringency relation, (see Section 2.1 \& endnote 5).

Three key rankings have not yet been established: Trochaic and ALIGN-HEAD/R, FTBIN and ALIGN-HEAD/R, and WSP and AFL. These are taken up in the next three sections.

\section{FTBIN $>>$ ALIGN-HEAD/R $>$ Trochaic}

Stress is always Trochaic as in the examples in (1. a, i, ii, iii). However, in words of more than two syllables, another constraint is at play. This constraint is ALIGN-HEAD/R, which ensures that stress docks on one of the rightmost syllables.

Tableau 10 illustrates the ranking between ALIGN-HEAD/ $\mathrm{R}$ and Trochaic and shows that ALIGN-HEAD/R is higher and dominates Trochaic.

The winner in (a) obeys FTBIN, ALIGN-HEAD/R and TROCHAIC. Other candidates incur crucial violations with the relevant constraints. For example, candidate (b) does not obey FTBIN, because it contains a degenerate foot [yá]. Candidate (c) on the other hand, loses because it violates ALIGN-HEAD/R by having the stress fall on the first syllable [?ís] and not on one of the three rightmost ones. Candidate (d) loses because it violates both FTBIN and ALIGN-HEAD/R, even though it satisfies TROCHAIC. Based on the principles of combination Tableau, both FTBIN and ALIGN-HEAD/R dominate TROCHAIC because there are two (Ws) on the left of the (L) which is in the TROCHAIC column of candidate (d).

Tableau 9.

ALIGN-HEAD/R >>PARSE- $\sigma$.

\begin{tabular}{lcc}
\hline /Pistiratijiyya/ & ALIGN-HEAD/R & PARSE- $\sigma$ \\
'strategy' & & $* *$ \\
oa. (Pis)(tira)ti(jíy)ya & & \\
b. (Pís)(tira)(ti)(jiy)(ya) & "W & $\mathrm{L}$ \\
\hline
\end{tabular}

Tableau 10.

FTBIN, ALIGN-HEAD/R $>>$ Trochaic (TR).

\begin{tabular}{lccc}
\hline $\begin{array}{l}\text { /Pistiratijiyya/ } \\
\text { 'strategy' }\end{array}$ & FTBIN & ALIGN-HEAD/R & TR \\
\hline oa. (Pis)(tira)ti(jíy)ya & & & \\
b. (Pis)(tira)ti(jiy)(yá) & ${ }^{*} \mathrm{~W}$ & & \\
c. (Pís)(tira)ti(jiy)ya & & ${ }^{*} \mathrm{~W}$ & \\
d. (Pis)(tíra)(tijiy)ya & ${ }^{*} \mathrm{~W}$ & ${ }^{*} \mathrm{~W}$ & $\mathrm{~L}$ \\
\hline
\end{tabular}


To sum up thus far, a direct ranking is found between the ALIGN-HEAD/R and Trochaic constraints as illustrated in Tableau 11, and between WSP and PARSE- $\sigma$, as demonstrated in Tableau 8. But the ranking relationship between ALIGN$\mathrm{HEAD} / \mathrm{R}$ and AFL still needs to be established. I propose that ALIGN-HEAD/R dominates AFL transitively. We have seen in Tableau 9 that ALIGN-HEAD/R dominates PARSE- $\sigma$, and in Tableau 5 that PARSE- $\sigma$ dominates AFL. Since ALIGN-HEAD/ $\mathrm{R}$ dominates PARSE- $\sigma$, and PARSE- $\sigma$ dominates AFL, then it is safe to assume that ALIGN-HEAD/R dominates AFL by means of transitivity. I also propose for the interaction between WSP and AFL that WSP dominates AFL by means of transitivity. In Tableau 6 WSP dominates PARSE- $\sigma$, and in Tableau 5 Parse- $\sigma$ dominates AFL; therefore, the ranking WSP $>$ AFL can be assumed by transitivity as well.

\section{Conclusion}

7) Primary Stress constraint hierarchy

FTBIN, ALIGN-Hd/R $>>$ TR $>>$ WSP $>>$ PARSE- $\sigma$, PARSE $\mathrm{SG} \gg$ AFL

As Tableau 11 demonstrates, certain constraints are un-dominated and highly ranked. These are FOOTBINARITY, and ALIGN HEAD/RIGHT. The data could not show a direct relationship between these two constraints, as illustrated by the dashed lines. The inviolability of these constraints is also asserted in the literature. For example, Watson (2002) discussed that CA does not allow a degenerate foot, and that a foot must be of two moras (i.e., bimoraic). FOOTBINARITY specifies that a foot must be bimoraic, and therefore; a syllable that has one mora is not parsed to the higher prosodic constituent, namely the foot. This explains why syllables e.g., ([mu in [mu(sal)(sála)], [mi] mi (šii)], and [ra] in [(šága)ra]) are not parsed into the foot.

ALIGN HEAD/RIGHT, which stipulates that primary stress must be on one of the three rightmost syllables, is also confirmed in the literature (Hayes, 1995; Kenstowicz, 1980; McCarthy, 1979, 1984; Watson, 2002). The other high ranked constraint is TROCHAIC. However, as observed, it is unlike the former un-dominated constraints, since it is dominated by ALIGN HEAD/RIGHT.

The analysis also discussed WEIGHT TO STRESS constraint. The summary Tableau shows that this constraint, in con-

Tableau 11.

Summary table.

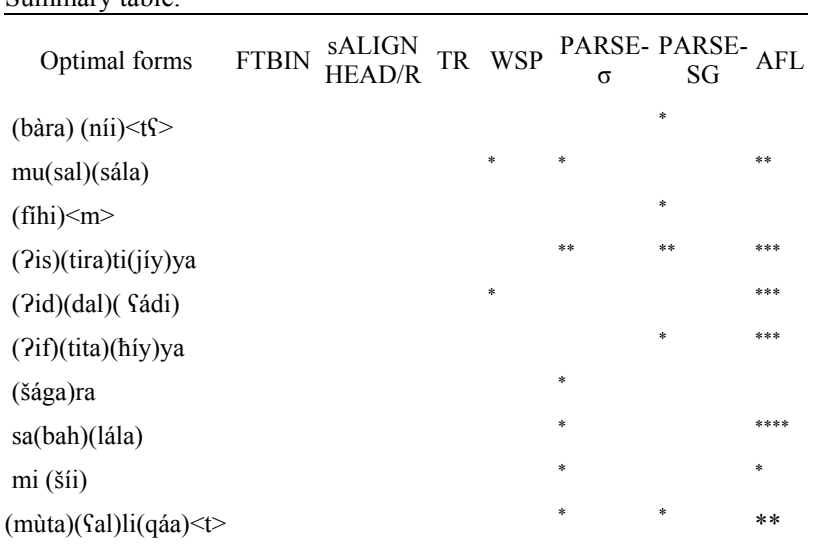

junction with ALIGN HEAD/RIGHT, explains stress on heavy penult syllables. WEIGHT TO STRESS constraint also domi nates PARSE- $\sigma$. In fact, PARSE- $\sigma$ is low ranked, and hence syllables that are of one mora are not parsed. With the analysis in this paper, findings in the literature concerning primary stress in CA are translated into an Optimality Theoretic framework illustrating the interaction between stress constraints.

\section{REFERENCES}

Badawi, E.-S., \& Hinds, M. (1986). A dictionary of Egyptian Arabic. Beirut: Librairie du Liban.

Chomsky, N., \& Halle, M. (1986, 1991). The sound pattern of English. Cambridge, MA: The MIT Press.

Gairdner, W. H. T. (1926). Egyptian colloquial Arabic: A conversation grammar (2nd ed.). London: Oxford University Press.

Halle, M., \& Vergnaud, J. R. (1987). An essay on stress. Cambridge, MA: The MIT Press.

Harms, R. (1981). A backwards metrical approach to Cairo Arabic stress. Linguistic Analysis, 7, 429-450.

Harrell, R. S. (1957). The phonology of colloquial Egyptian Arabic. New York: American Council of Learned Societies.

Hayes, B. (1995). Metrical stress theory: Principles and case studies. Chicago: University of Chicago Press.

Kenstowicz, M. (1980). Notes on Cairene Arabic syncope. Studies in the Linguistic Sciences, 10, 39-53.

Kenstowicz, M. (1994). Phonology in generative grammar. Cambridge, MA: Blackwell.

Liberman, A. M., \& Prince, A. (1977). On stress and linguistic rhythm. Linguistic Inquiry, 8, 249-336.

McCarthy, J. (1979). On stress and syllabification. Linguistic Inquiry, 10, 443-466.

McCarthy, J. (2008). Ther serial interaction of stress and syncope. Natural Language and Linguistic Theory, 26, 499-546. doi: 10.1007/s11049-008-9051-3

McCarthy, J., \& Prince, A. (1986). Prosodic morphology. Boston, MA: University of Massachusetts.

McCarthy, J., \& Prince, A. (1990). Prosodic minimality. Urbana-Champaign: The Organization of Phonology. University of Illinois.

McCarthy, J., \& Prince, A. (1993a). Generalized alignment. In G. E. Booij, \& J. V. Marle (Eds.), Yearbook of morphology (pp. 209-153). Dordrecht: Kluwer.

McCarthy, J., \& Prince, A. (1993b). Prosodic morphology I: Constraint interaction and satisfaction. Amherst, MA: University of Massachusetts.

Mitchell, T. F. (1956). An introduction to Egyptian coloquial Arabic. New York: Oxford University Press.

Mitchell, T. F. (1960a). Prominence and syllabification in Arabic. Bulletin of the School of Oriental and African Studies, 23, 369-389. doi:10.1017/S0041977X00149997

Prince, A. (1980). A metrical theory for Estonian Quantity. Linguistic Inquiry, 11, 511-562.

Prince, A. (1983). Relating to the grid. Lingistic Inquiry, 14, 19-100.

Prince, A. (2002). Arguing optimality. In A. Carpenter, A. Coetzee, \& P. D. Lacy (Eds.), University of Massachusetts occasional papers in linguistics 26: Papers in Optimality Theory II (pp. 269-304). Amherst, MA: GLSA Publications.

Prince, A., \& Smolensky, P. (1993). Optimality theory: Constraint interaction in generative grammar. Boulder, $\mathrm{CO}$ : University of Colorado.

Selkirk, E. (1984). Phonology and syntax: The relation between sound and structure. Cambridge, MA: The MIT Press.

Watson, J. C. E. (2002). The phonology and morphology of Arabic. Oxford, AL: Oxford University Press.

Welden, A. (1980). Stress in Cairo Arabic. Studies in the Linguistic Sciences, 10, 99-120. 